\title{
Pembinaan Wawasan Kebangsaan Berbasis Kearifan Lokal Bagi Guru di Madrasah Tsanawiyah Muhammadiyah Patikraja
}

\author{
Elly Hasan Sadeli ${ }^{\mathrm{a}, 1}$, Akhmad Fauzan ${ }^{\mathrm{b}, 2}$ \\ ${ }^{\mathrm{a}, \mathrm{b}}$ Fakultas Keguruan dan Ilmu Pendidikan, unversitas Muhammadiyah Purwokerto, Banyumas* \\ ${ }^{1}$ ellyhasansadeli85@gmail.com; ${ }^{2}$ masfau2018@gmail.com \\ *Korespondensi Penulis
}

Naskah diterima: 20 Maret 2021 , direvisi: 25 Maret 2021 , disetujui: 28 Maret 2021

\begin{abstract}
Abstrak
Menumbuhkah wawasan kebangsaan memiliki peran yang sangat strategis dalam membangun idealisme yang melekat pada diri seseorang. Termasuk profesi guru, perlu penanaman pemahaman sebagai bangsa yang bersatu dalam realitas kebhinekaannya. Wawasan kebangsaan diharapkan dapat melahirkan satu sikap nasionalisme, seperti memiliki rasa bangga terhadap bangsanya, mencintai tanah air, menjalankan kewajiban sebagai warga negara dan menghargai setiap keberagaman yang melekat dalam kehidupan bermasyarakat. Wawasan kebangsaan dalam bingkai kegiatan pengabdian ini juga merupakan salah satu usaha untuk membentuk, menanamkan dan membina wawasan kebangsaan bagi guru MTs Muhammadiyah Patikraja. Melalui pengabdian ini, guru diharapkan memiliki pengetahuan, pemahaman dan kesadaran akan pentingnya wawasan kebangsaan dalam menjaga stabilitas kehidupan yang plural. Sehingga dapat diimplementasikan dalam proses pembelajaran di sekolah guna merawat dan memupuk semangat menjaga harmonisasi keberagaman.
\end{abstract}

Kata Kunci : wawasan kebangsaan dan nasionalisme

\begin{abstract}
Cultivating national insight has a very strategic role in building the idealism inherent in a person. Including the teaching profession, it is necessary to cultivate understanding as a united nation in the reality of its diversity. The national insight is expected to give birth to an attitude of nationalism, such as having a sense of pride for the nation, loving the homeland, carrying out obligations as citizens and respecting every diversity inherent in social life. Insight of nationality in the framework of this service activity is also one of the efforts to form, instill and foster national insight for teachers of MTs Muhammadiyah Patikraja. Through this service, teachers are expected to have knowledge, understanding and awareness of the importance of national insight in maintaining the stability of a pluralistic life. So that it can be implemented in the learning process in schools in order to care for and foster the spirit of maintaining the harmonization of diversity.
\end{abstract}

Keywords: national insight and nationalism 


\section{PENDAHULUAN}

Wawasan kebangsaan merupakan komitmen bersama dalam rangka menjaga situasi dan kondisi kehidupan masyarakat yang nyaman serta memiliki dampak untuk menjaga stabilitas kemajemukan yang telah lama muncul di Indonesia. Pengetahuan dan pemahaman tentang wawasan kebangsaan menjadi hal yang sangat penting bagi seluruh masyarakat. Di tengah situasi dan kondisi yang sangat dinamis, seiring dengan proses kehidupan masyarakat yang terus bergerak, sehingga peranan wawasan kebangsaan memiliki peran yang sangat strategis dalam menjaga dan merawat stabilitas kondisi berbangsa dan bernegara.

Selain itu, kehadiran era globalisasi yang saat ini mulai meluluhlantahkan tatanan tradisi kehidupan masyarakat yang ada. Kondisi ini tentu saja tidak dapat dihindari, namun tetap perlu diwaspadai, karena selain memberikan dampak secara positif, globalisasi juga dapat memberikan dampak yang negatif. Proses globalisasi ditandai dengan perkembangan teknologi, informasi dan komunikasi yang pesat dan mempengaruhi semua bidang kehidupan suatu negara, baik ideologi, politik, ekonomi, sosial budaya dan pertahanan keamanan suatu negara, termasuk Indonesia. Bagi bangsa Indonesia, pengaruh globalisasi telah membawa nila-inilai universal (individualisme, hedonisme dan liberalisme) yang melunturkan nilai-nilai nasional (gotong royong, tenggang rasa dan sopan santun) sehingga menggeser pola pikir dan pola tindak masyarakat khususnya remaja (Rahmanto dan Yani, 2015:1369).

Sebelum kemunculan globaliasasi, seyogyanya bangsa Indonesia sedang mengalami persoalan yang sangat kompleks, salah satunya masalah krisis kebangsaan yang ditunjukkkan oleh adanya lemahnya tata kelola bernegara, bahkan kondisinya sudah mulai menjauh dari apa yang telah diamanatkan oleh Undang-Undang Dasar Negara Republik Indonesia (UUD NRI) 1945 yaitu, untuk mencerdaskan dan mensejahterakan seluruh masyarakat Indonesia. Namun, alih-alih menjalankan amanat konstitusi, bangsa ini justru disibukkan oleh hal yang bisa memecah belah persatuan dan kesatuan. Misalnya saja permasalahan beda pilihan dalam kontestasi pemilu. Bahkan muncul polarisasi kelompok dengan sebutan cebong dan kampret. Sementara para elit juga lebih banyak dihadapkan pada pertikaian dalam memperebutkan kekuasaan, sehingga persoalan kenegaraan dan kebangsaan yang sejatinya perlu mendapatkan perhatian menjadi terabaikan.

Oleh karena itu, ditangan pemudalah estafet kepemimpinan menjadi semakin kuat 
disaat adanya kaderisasi yang sehat. Bahkan Bung Karno dengan tegas mengatakan, "Seribu orang tua hanya dapat bermimpi, satu pemuda dapat mengubah dunia." "Berikan aku 1000 orang tua, niscaya akan kucabut semeru dari akarnya, berikan aku satu pemuda, niscaya akan kuguncangkan dunia”. Berdasarkan pandangan dari tersebut maka perlu dibangun proses regenerasi secara berkesinambungan. Sehingga calon pemimpin dimasa yang akan datang mampu memberikan dampak yang positif terhadap kemajuan bangsa dan negara.

Adanya kemajemukan di Indonesia jika tidak dikelola secara proporsional, akan melahirkan suatu ancaman terhadap disintegrasi bangsa. Bahkan ancaman itu mulai muncul kembali memperngaruhi kebhinekaan bangsa dalam bentuk pola represif atas nama agama, suku dan pilihan politik masih terjadi sampai sekarang.

Sejarah menunjukkan bahwa, bangsa ini pernah mengalami kejayaan sistem pengelolaan negara yang saat itu menggunakan bentuk kerajaan. Namun prinsip semangat kebangsaan belum tercipta, yang kemudian dimanfaatkan oleh negara lain dengan cara dilumpuhkan melalui politik pecah belah dan memunculkan keberhasilan kolonialisme.

Proses perjalanan panjang perjuangan berubah menjadi lebih modern, para pejuang meletakan sikap primordialisme dan ego kesukuan maupun agama sebagai strategi untuk melawan segala bentuk kolonialisme. Maka munculah benih-benih kebangsaan itu dalam momentum kebersamaan melalui beberapa organisasi. Hal ini justru makin memperkuat ikatan emosional baik kaum muda maupun yang tua. Bahkan momentum yang paling monumental dalam membangun kerangka kebangsaan itu lahir dari semangat dan prinsip para pemuda dalam satu tekad yang sama melalui sumpah pemuda pada tahun 1928, jauh sebelum negara Indonesia merdeka diproklamasikan.

Hal ini menunjukkan bahwa daya dorong para perintis kemerdekaan pada prinsipnya telah memiliki titik temu yang satu secara kolektif untuk membentuk suatu bangsa yang melepaskan segala perbedaan demi tujuan yang sama mengantarkan kemerdekaan bagi seluruh masyarakat.

Kemajuan jaman yang sangat dinamis tentu akan mempengaruhi seluruh aspek kehidupan masyarakat. Saat ini seluruh negara di dunia sedang dihadapkan pada kompetisi untuk menunjukkan keunggulan masing-masing negara. Jika bangsa Indonesia hanya menjadi penonton, maka ancaman itu akan lebih mudah masuk memberikan dampak yang negatif bagi masyarakat yang belum siap untuk bersaing. Bisa dilihat bagaimana bangsa ini kemudian 
larut dalam ketidakberdayaan, prinsip-prinsi kebangsaan yang telah dibentuk, mulai diabaikan. Nilai-nilai kebaikan bersama perlu kembali dipahamkan sebagai pondasi utama dalam membangun negeri ini.

Oleh karena itu, membina wawasan kebangsaan merupakan hal yang cukup esensial untuk mengantisipasi segala bentuk ancaman dari kehidupan yang dinamis saat ini. Sehingga diharapkan dapat membentuk karakter bangsa yang kokoh guna lebih mencintai dan menghargai bangsanya. Sudah selayaknya rasa kebangsaan dirawat melalui proses pendidikan yang terencana dan terpadu. Sehingga melahirkan kekuatan ikatan kebersamaan dalam bingkai keberagaman yang harmonis.

Konsep wawasan kebangsaan sejatinya berangkat dari semangat kebersamaan dalam kondisi kesengsaraan dan berusaha untuk menyelesaikan persoalan secara kolektif. Sebagaimana dikemukakan Nasikun (2006:1) yang memandang wawasan kebangsaan sebagai suatu gerakan ideologis, yang muncul dari akibat peristiwaperitiwa "anteseden" yang telah terjadi sebelumnya. Sejarah kesadaran kebangsaan di benua Asia, Afrika dan Amerika latin yang dikenal sebagai kawasan dunia ketiga, timbul dari persamaan nasib akan penderitaan yang dialami bersama-sama.
Khusus pada bangsa Indonesia, unsur-unsur wawasan kebangsaan berangkat dari keadaan masyarakat yang plural dan heterogen, kemudian memunculkan rasa kebangsaan, paham kebangsaan dan semangat kebangsaan atau nasionalisme (Amal dan Armawi, 1998:12).

Maka, secara tidak langsung pijakan wawasan kebangsaan terdiri dari tiga komponen utama, yaitu tentang pemahaman yang utuh terhadap bangsa dan kebangsaan, memiliki rasa serta prinsip semangat kebangsaan (Depdiknas, 2009:30). Tergambar secara jelas bahwa Pancasila, UUD NRI 1945, Bhinneka Tunggal Ika dan NKRI merupakan landasan wawasan kebangsaan bagi bangsa Indonesia dan kemudian disepakati sebagai dasar persatuan. Maka, unsur-unsur wawasan kebangsaan tersebut dijadikan indikator dalam kegiatan pengabdian tentang wawasan kebangsaan bagi para guru.

Maka komponen target kegiatan pengabdian ini terdiri dari :

a. Mengembangkan pengetahuan guru MTs Muhammadiyah Patikraja tentang wawasan kebangsaan

b. Meningkatkan pemahaman guru MTs Muhammadiyah Patikraja tentang wawasan kebangsaan

c. Membina sikap kebangsaan dalam kehidupan sehari-hari 
Kegiatan ini di harapkan akan senantiasa dipupuk dan dipelihara secara terencana dan terpadu khususnya bagi guru MTs Muhammadiyah Patikraja dalam memahami wawasan kebangsaan, sehingga jangka panjang dari kegiatan ini juga diharapkan mampu memberikan pengaruh yang optimal bagi peserta didik supaya memiliki kecintaan terhadap tanah air.

Oleh karena itu, kami melakukan sosialisasi pada guru MTs Muhammadiyah Patikraja, agar mereka memahami tentang pentingnya kesadaran membina wawasan kebangsaan. Oleh karena itu, marilah kita bersama-sama mewujudkan suatu generasi yang taat pada hukum dan cinta kepada negara dengan menumbuhkan rasa kesadaran sikap nasionalisme di dalam diri kita agar terciptanya sebuah kebanggaan bersama terhadap bangsa dan negara Indonesia.

Kerangka penyelesaian masalah yang telah dilaksanakan adalah:

a. Mengadakan sosialisasi untuk penguatan pengetahuan wawasan kebangsaan.

b. Mengadakan sosialisasi untuk penguatan pemahaman wawasan kebangsaan

c. Memberikan pemantapan wawasan kebangsaan yang berintikan Pancasila, UUD NRI 1945, NKRI dan Bhineka Tunggal Ika yang merupakan pedoman berbangsa dan bernegara d. Memberikan contoh sumber inspirasi keteladanan dari tokoh pendiri bangsa yang bertujuan untuk memotivasi dan mengarahkan proses penyelenggaraan kehidupan yang mampu membangun kondisi yang harmonis.

e. Sebagai fasilitator dalam rangka penanaman sikap kebangsaan yang berbasis pada konsep kearifan lokal (local wisdom).

\section{METODE}

Pelaksanaan kegiatan pengabdian dilakukan pada hari Kamis, 18 Maret 2021 pukul 13.00 di ruang komputer MTs Muhammadiyah Patikraja. Kegitan meliputi Pemberian soal pre tes dan dilanjutkan penjelasan materi pengabdian kemudian diakhiri dengan pemberian soal post tes. Khalayak sasaran dari pengabdian ini adalah guru-guru MTs Muhammadiyah Patikraja.

Metode pendekatan pada kegiatan ini adalah:

a. Mengadakan sosialisasi untuk penguatan pengetahuan tentang wawasan kebangsaan pada masyarakat.

b. Mengadakan sosialisasi untuk penguatan pemahaman pentingnya wawasan kebangsaan dalam kehidupan bermasyarakat

c. Memberikan motivasi melalui cerita sejarah perjuangan tentang konsep wawasan kebangsaan dalam rangka 
meningkatkan pengetahuan dan

pemahaman masyarakat

d. Sebagai fasilitator dalam rangka pembinaan pemahaman wawasan kebangsaan bagi masyarakat.

e. Evaluasi program.

\section{HASIL DAN PEMBAHASAN}

Untuk membina

wawasan

kebangsaan diperlukan proses budidaya pendidikan secara berkelanjutan. Maka, lingkungan pendidikan yang ideal adalah sekolah dan keluarga. Proses pendidikan di lingkungan ini memiliki peran yang penting dalam pembinaan wawasan kebangsaan. Berdasarkan hasil penelitian William Bennet (Wibowo, 2012:54) diungkapkan bahwa peserta didik lebih lama menghabiskan waktu di sekolah daripada di rumah, sehingga apa yang terekam dalam memori peserta didik di sekolah ternyata memiliki pengaruh besar bagi kepribadian mereka ketika dewasa kelak.

Oleh karena itu, sebagai bangsa yang memiliki keberagaman, maka urgensi menanamkan rasa persatuan, kesatuan dan persaudaraan merupakan upaya yang harus diwujudkan sejak dini. Sehingga dapat menunjang tercapainya cita-cita dan tujuan nasional berdasarkan konstitusi.

Untuk menwujudkan cita-cita dan tujuan nasional tersebut diperlukan komitmen dan loyalitas dari bangsa itu sendiri, salah satunya adalah dengan membentuk dan menumbuhkembangkan kesadaran rasa kebangsaan. Untuk membangun wawasan kebangsaan harus berpijak dari komitmen warga negaranya. Selama warga negaranya memiliki idealisme sebagai bangsa yang bersatu dalam realitas kebhinekaannya, maka kesadaran akan wawasan kebangsaan lebih mudah terbentuk.

Berdasarkan hasil pengabdian yang telah dilaksanakan, terlihat peserta cukup antusias dan aktif tanya jawab, bahkan mereka mengharapkan kegiatan seperti ini berlanjut.

Gambar 1. Peserta sedang Menyimak

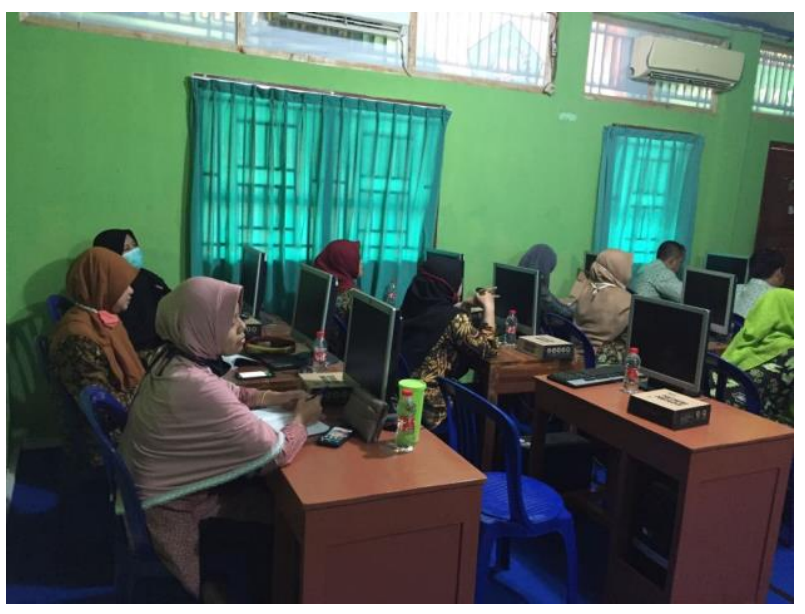

Hasil dari pengabdian ini, peserta semakin memahami pentingnya membina wawasan kebangsaan.

Gambar 2. Penjelasan Materi

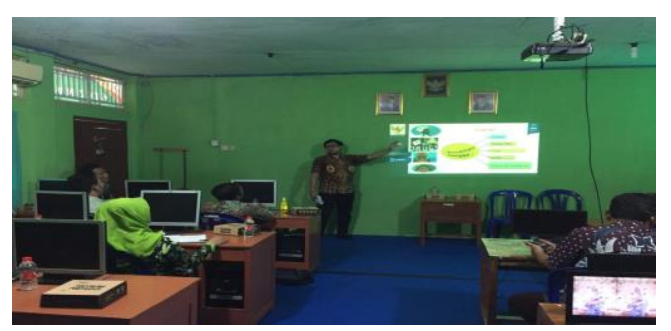


Berikut hasil pengolahan data pre test dan post test tentang wawasan kebangsaan yang dimiliki oleh guru MTs Muhammadiyah Patikraja.

Diagram 1 Hasil Pre Tes dan Pos Tes

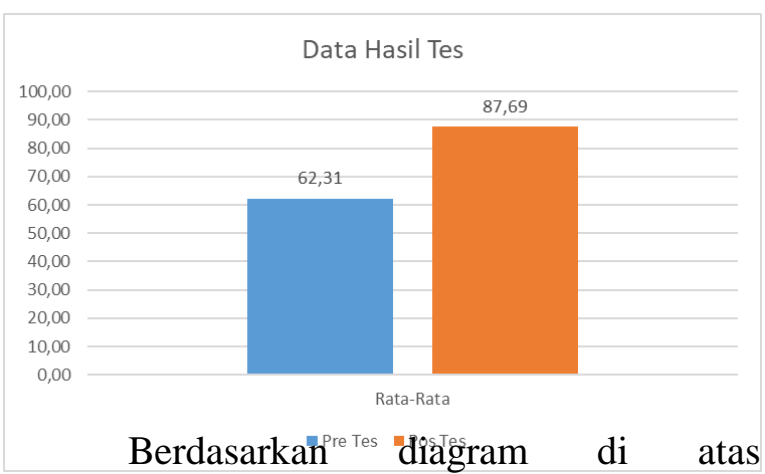

menunjukkan bahwa setelah mendapatkan pembinaan wawasan kebangsaan, pemahaman pada guru mengalami peningkatan dari pre tes sebesar $62,31 \%$ dan post tes $87,69 \%$. Pengetahuan yang dimiliki oleh guru mengalami peningkatan sebesar $25,38 \%$.

Berdasarkan diagram di atas dapat dipahami bahwa kegiatan sosialisasi pada seluruh guru di MTs Muhammadiyah Patikraja, memberikan dampak yang positif khususnya dalam memahami wawasan kebangsaan dan pentingnya kesadaran membina wawasan kebangsaan serta kemudian secara kolektif berupaya membangun generasi yang sadar akan hak dan kewajiban yang didasari cinta kepada negara. Serta menanamkan kesadaran akan sikap nasionalisme bersama, agar terciptanya sebuah kebanggaan bersama terhadap bangsa dan negara Indonesia.
Upaya untuk meningkatkan rasa kebangsaan bagi setiap anggota masyarakat merupakan hal penting. Sebagaimana dikemukakan oleh Amal dan Armawi (1998:12) yang menjelaskan bahwa rasa kebangsaan merupakan perekat paling dasar dari setiap anggota masyarakat bangsa yang karena sejarah dan budayanya memiliki dorongan untuk menjadi satu dan bersatu tanpa pamrih di dalam satu wadah negara bangsa (nation-state). Ungkapan rasa kebangsaan diwujudkan dalam bentuk Sumpah Pemuda pada tanggal 28 Oktober 1948. Sumpah pemuda merupakan peristiwa bersejarah yang membanggakan dan mempersatukan seluruh anak bangsa Indonesia dari Sabang sampai Merauke yang multi etnis, suku dan budaya dalam satu tanah air,satu bangsa dan satu bahasa. Rasa kebangsaan dalam diri seluruh bangsa Indonesia yang mempersatukan tanah air, bangsa dan bahasa inilah yang perlu dijaga, diperkuat dan ditingkatkan terutama bagi siswa sebagai generasi penerus bangsa.

Maka luaran yang didapatkan melalui kegiatan ini antara lain pengetahuan, pemahaman dan kesadaran guru dalam memaknai wawasan kebangsaan secara komprehensif dan implementatif. 


\section{KESIMPULAN}

1) Kesimpulan

Kegiatan Pengabdian tentang wawasan kebangsaan memberikan dampak positif bagi guru dalam meningkatkan kompetensi tentang konsep wawasan kebangsaan. Sehingga memiliki kesadaran akan tanggung jawab sebagai bagian dari warga negara dan mampu memberikan keteladanan bagi peserta didik.

2) Saran

Kepada kepala sekolah dan guru agar senantiasa memberikan tauladan yang baik pada seluruh masyarakat, khususnya mengenai sikap cinta tanah air, sehingga cita-cita dan tujuan negara dapat tercapai.

\section{REFERENSI}

Amal, I dan Armawi, A. 1998. Regionalisme, Nasionalisme, dan Ketahanan Nasional. Yogyakarta: Gadjah mada University Press.

Depdiknas. 2009. Panduan Pelaksanaan Pendidikan Berwawasan Kebangsaan di Sekolah Menengah Pertama.

Retrieved

fromhttp://file.upi.edu/Direktori/FIP/J

UR._PEDAGOGIK/195009081981011

Y._SUYITNO/PANDUAN_SIAP_DI

KWASBANG_JADI.pdf

Nasikun. 2006. Wawasan Kebangsaan di Bawah Tekanan Globalisasi dan Kebangkitan Kembali Politik Aliran. Jurnal Ketahanan Nasional, No.XI (1), 1-29. Retrieved fromhttps://jurnal.ugm.ac.id/jkn/article /view/22106

Wibowo, Agus. 2012. Pendidikan Karakter Strategi Membangun Karakter Bangsa Berperadaban. Yogyakarta: Lembaga Penerbit Pustaka Pelajar 
Jurnal Loyalitas Sosial Vol. 3 No. 1 Maret 2021
Journal of Community Services in Humanities and Social Sciences p-ISSN 2655-9072 | e-ISSN 2686-1380 